\title{
Participation of academics with disabilities in science using the example of AKTIF project
}

\author{
Sinem Ulutas ${ }^{1}$, Susanne Groth ${ }^{1}$, Wolfgang Thiems ${ }^{1}$, and Mathilde Niehaus ${ }^{1}$ \\ ${ }^{1}$ Universität zu Köln, Lehrstuhl für Arbeit und berufliche Rehabilitation, Herbert-Lewin Straße 2, \\ 50931 Köln
}

\begin{abstract}
This paper discusses the participation in the scientific world by referring to the AKTIF project. It introduces how the research team of AKTIF takes on the problems of academics with disabilities and reflects on the participation in one's own team. AKTIF project suggests that for a successful outcome of the participation in the academy, conditions of the recruitment process, employment intake, as well as the cooperation within the course of the project should be changed.
\end{abstract}

Keywords: AKTIF project; academics with disabilities; academy

\section{Introduction}

The relevance of the subject participation is based on the fact that in the future, academics with disabilities, as a result of a more inclusive educational and work system, will be increasingly represented in science. It is noticeable, however, that people with disabilities, even if they achieved a university degree, do not benefit as much from career advancement opportunities as people without disabilities who have an identical level of education ([1]; [2]). Therefore, this article concerns the inclusion or involvement of highly qualified people with disabilities in science.

Currently there is little information available in Germany concerning their involvement in scientific research, especially with regard to the area of participation and inclusion research. However, the available data and information material on the general labor market situation of persons with disabilities, on their participation in higher education [3], as well as on the observed interrelations of employment and educational opportunities suggests that the integration of this group into research enterprises is relatively weak. Even in the context of current participation and inclusion research, academics with disabilities seem to play a subordinate role as an active researcher as they are usually included as consultants. This paradoxical situation does neither meet the subject itself nor the requirements of full participation of people with disabilities. Furthermore, they could be far more engaged in the context of education and research in the field. From this point of view, the question as to which conditions must be met for a successful participation in the scientific work will be approached. 
With the ratification of the United Nations Disability Equality Convention (UN-DEC) in 2009, Germany has committed itself to strengthening the autonomy and selfdetermination of people with disabilities, ensuring equal opportunities and accessibility as well as promoting full and effective participation in all areas of society. Article 24 (Education) and Article 27 (Work and Employment) provide for the establishment of concrete measures which should contribute to the participation in science in the future. In order to ensure this, besides addressing structural and technical issues, it is crucial to consider "barriers in the head" as well [1]. This indicates that all persons who are active in the field of science should break down prejudices and question stereotypes in order to make participation possible. Dealing with diversity in the field of science involves new challenges, which are described below. Yet, no research has shown how the participation of disabled academics in the scientific world can succeed, the challenges they face, and which prerequisites are needed for successful participation. First of all, this article shows how the research team of AKTIF takes on these problems and reflects on the participation in one's own team. Next, the relevance of this project and its initial situation will be clarified. Subsequently, the question of what constitutes participation in research and science will be discussed. In this way, the participatory development process can be exemplified in the course of the AKTIF project. Following a general reflection, the main findings are summarized in a conclusion and an outlook is given.

\section{Background and starting point}

Within the scope of the AKTIF project (academics with disabilities in participation and inclusion research), an inclusive, interdisciplinary network of researchers, who deal with issues of inclusion and participation research, is being developed at four locations throughout Germany. The main goal is to ensure that people with disabilities themselves and their organizations are involved in participation research as far as possible. At least half of the employees of the individual research teams have severe disabilities themselves. Within the framework of the project, funded by the German Federal Ministry of Labor and Social Affairs in 2015, scientists with and without disabilities jointly identify relevant research gaps and key issues. The aim of AKTIF is to promote opportunities for severely disabled academics in the scientific field: among other things, higher education, acquisition of and participation in inclusive externally funded projects and establishment in science at the university. It is expected that this will have an innovative thrust and a radiant power for the entire participation and inclusion research and will further promote research in the long term. In addition, the career prospects and the positions of qualified disabled academics in this future-oriented research area will be further developed, and insurable employment areas will be created for them. At the Cologne office, the Chair of Labor and Vocational Rehabilitation deals with issues related to the participation of people with disabilities in the scientific world. The chair represents an application-oriented and interdisciplinary approach to research and teaching. Pedagogical, psychological and social approaches of the vocational and social participation of people with disabilities and health problems are interlinked in science and practice.

The research approach is based on a participation-oriented understanding, which takes account of the perceptions and requirements of participating stakeholders and their involvement in the research process. Against this backdrop, a contribution was made by the AKTIF Cologne team, following a participatory research approach, to deal with the specific concern of participation in science. 


\section{What is meant by participation in science?}

Essentially, scientists analyze the term "participation" and the concepts behind it by means of different approaches and systematization possibilities. Contingent on the subject and on the discipline one is socialized, the concept of participation is specifically accentuated. Participation does not refer solely to economic empowerment, but also to the political dimension (i.e. possibilities of influence) as well as to social dimensions (such as the degree of social inclusion or networking) [4]. Thus, participatory research is less an approach but a strategy and implies "to transfer the claim of participation to scientific research" [5]. Unger [6] extends that in order to change social reality, the diverse multitude of research approaches needs to be incorporated. An extension to target groups and individuals with special knowledge is quite possible [7]. Therefore, a distinction can be drawn between emancipatory research (active researchers with own research questions), participatory research (researchers are equally entitled), and research (active shapers of the research field and course) [8].

In participatory research, for example, academics with and without disabilities can cooperate or form alliances. The research question itself has to be in the (cognitive) interest of people with disabilities and research has to be conducted jointly by researchers with and without disabilities [9]. Thus, participatory research pursues the appropriate exploration of participation, but is also concerned with the realization of participation in the research process itself. . As educational scientists, psychologists, social scientists and sociologists, we will approach this particular perspective and way of thinking about participation. In this article, it is therefore assumed that participation in the research process increases the chances of academics with disabilities in research and science. Against this background, the work within the AKTIF project has highlighted three participation-oriented approaches and can be read as follows:

1.For equal opportunities in participation in science the creation of jobs is needed.

2.To ensure that academics with disabilities continue to participate in science, further qualifications are of particular importance.

3. To enable academics with disabilities to develop their potential in science, it is necessary that new steps will be taken to improve accessibility.

\section{Conditions for successful participation in science - using the example of AKTIF}

With regard to the realization and implementation of the three emerging approaches from the AKTIF project and a systematic evaluation of the experience reports created by the individual team members in 2015 and 2016 on the recruitment process at the university, the employment and cooperation in the course of the project, the following can be concluded for the location in Cologne: The original purpose of the experience reports was to document the problems with the formation of inclusive research teams and the possible solutions already exist (best practice examples). The reports were once again systematically evaluated for the research project with regard to the challenges and conditions for participation in science work for disabled academics. The analysis of the experience reports differentiated between individual and collective challenges. When working at the University of Cologne, academics with disabilities were confronted with numerous additional organizational tasks. These tasks were related both directly and indirectly to the pursuit of their activities. In order to be able to work in a barrier-free way, different workplaces were applied for participation in working life at the Federal Employment Agency. The application and the procedure took additional temporal resources, partly because some responsibilities were initially unclear. The inclusion of the new activity in the 
field of science also called for a particularly high degree of flexibility for the disabled. By relocating to a new city, the employees with mobility and visual impairment were particularly challenged to find themselves in a very short time in a new infrastructure and to seek a new support network. In the workplace, the requirement of barrier-free communication was one of the biggest challenges for the entire team. Two academics with visual impairments met team members who had little experience working with visually impaired people. Over time, the team has learned to verbalize visual information, talk in structured meetings, make PDF documents barrier-free, dispense with the use of software that is not barrier-free, and e.g. how to successfully plan and take barrier-free business trips. For all project members it was also shown that a forward planning is particularly important for participation. This means, for example, that internal and external meetings are announced at an early stage so that barrier-free travel and accommodation can be organized and the deployment of personnel / technical support can be organized. Through the influence and co-determination in the research and science enterprise, a high commitment and a high degree of engagement arose. Prerequisites for securing participation are contact management and the equal distribution of information [10].

Participation in science is a relatively recent research area. On the way to an independent discipline, the development of specific research questions on the topic of disability during studies is of great importance. In this way, a new sensibility is being developed and visions and actions for the aspects of inclusion and participation of people with disabilities are mediated. We work together as a multidisciplinary team of psychologists, educators, and social scientists in an interdisciplinary manner. We corporate as a team to apply for inclusive research projects and to develop an inclusive research network.

\section{Reflection}

Participation in the scientific community may initially pose an additional expense in terms of time and organization, but this is more than offset by the synergies due to the very supportive and good cooperation. Through the participation, a well-functioning team with flat hierarchical structures and a forward-looking research stint, which acts innovative, inclusive, participatory and networking, is experienced. There is room for the individual, as well as a collective implementation and organisation of tasks. In order to guarantee accessibility, more financial and temporal resources are needed, but the innovative nature of the topics and outputs, the effectiveness and the quality of the work in these researches are very fruitful and beneficial for science, politics and society. In order to meet requirements, a planning of additional organization and technical aids is necessary.

Organizational challenges arise from the fact that barrier-free work materials, teaching materials and learning materials are not standardized as a special requirement and have to be "initiated". Special technical preparations must be prepared before each meeting or social event. For a successful communication and a good social co-operation, each team member is required a great sensitivity and attention for his co-workers and a great discipline.

\section{Conclusion}

In the coming years, the topic of "participation in the scientific enterprise" will become more relevant in practice and in research. In this article it was shown that participation is not only concernced with the transformation of social structures, but also with the consciousness formation of individuals. Especially, communication with each other is particularly important to work equally, effectively and innovatively, and what is more, to 
build and stabilize teamwork, so that joint research will be possible and social reality can be changed. In this context, "barriers in the minds" can be dismantled, as a rethinking is necessary. The participation of academics with disability can be achieved in the research and in the scientific enterprise, as soon as the cooperation and the alliances are also used as an opportunity. The research question itself must be in the (knowledge) interest of people with disabilities. Considering that, the normality of one's perception has to be be recognized and traditional notions of normality must be questioned. This indicates that one's own communication styles and assumptions must be reflected [11].

In conclusion, it can be stated the AKTIF project sucessfully demonstrated that inclusive work teams, adequate communications styles, as well as reflected assumptions [11] mutually contribute to the redefinement of the participative concept of work performance.

\section{References}

1. M. Niehaus, J. Bauer, Chancen und Barrieren für hochqualifizierte Menschen mit Behinderung: Übergang in ein sozialversicherungspflichtiges Beschäftigungsverhältnis - Pilotstudie zur beruflichen Teilhabe (Aktion Mensch e.V., ed.) (2013).

2. H.W. Bach, Berufliche Partizipation blinder, sehbehinderter und mehrfach behinderter Hochschulabsolventen in Deutschland, der Einfluss von Beratung - eine empirische Studie (2011) Retrieved from http://www.hdba.de/uploads/tx_sbdownloader/Berufliche_Partizipation_Text.pdf.

3. H. Pfaff, Lebenslagen der behinderten Menschen. Ergebnis des Mikrozensus 2009. Wirtschaft und Statistik 3rd ed., 232-243 (2012). Wiesbaden: Statistisches Bundesamt. Retrieved from https://www.destatis.de/DE/Publikationen/WirtschaftStatistik/Sozialleistungen/Lebensla genbehinde rte032012.pdf? blob=publicationFile.

4. G. Biewer, Grundlagen der Heilpädagogik und Inklusiven Pädagogik. 2nd ed. (2010).

5. P. Flieger, Partizipatorische Forschung: Wege zur Entgrenzung der Rollen von ForscherInnen und Beforschten. In: J. Kerg, K. Merz-Atalik, R. Thümmler \& H. Tiemann (Eds.), Perspektiven auf Entgrenzung. Erfahrungen und Entwicklungsprozesse im Kontext von Inklusion und Integration 59- 171 (2009).

6. H. Unger, Partizipative Forschung: Einführung in die Forschungspraxis (2014).

7. P. Flieger, Partizipative Forschungsmethoden und ihre konkrete Umsetzung. In G. Hermes \& S. Köbsell (Ed.), Disability Studies in Deutschland - Behinderung neu denken. Dokumentation der Sommeruni, 200-204 (2003).

8. S. Krach, Partizipative Evaluation als Beitrag zur Praxisentwicklung. Teilhabe. 1 (50), 11-16. (2011).

9. Chappell, Emergence of participatory methodology in learning difficulty research: understanding the context. In: British Journal of Learning Disabilities 28, S. 38-43 (2000).

10. F.C. Brodbeck, Anderson, N. \& West, M. Teamklima Inventar (TKI) (2000).

11. C. Behrens, U. Sielert, N. Hofmeister, N., Difference Troubles - Pädagogik der VielfaltArbeitsgruppe Primäre Prävention von Gewalt gegen Gruppenangehörige. Materialsammlung: Workshop Reader, 13-20 (2003), Retrieved from http://www.kriminalpraevention.de/files/DFK/dfkpublikationen/2003_workshop_reader.pdf. 